\title{
Profile of Xiaofeng Cao
}

Dr. Xiaofeng Cao obtained her B.S. degree in Applied Biochemistry from Peking University in 1988. She received her M.S. degree (supervised by Mr. Longfei Yan) in Biochemistry from China Agricultural University in 1991. From 1993 to 1997, she carried out her Ph.D. study (supervised by Dr. Zhangliang Chen) in the National Laboratory of Protein Engineering and Plant Genetic Engineering in the College of Life Sciences, Peking University. From 1995 to 1996, Dr. Cao was a visiting scholar in Liam Dolan's lab at John Innes Centre, UK. After completing her Ph.D. research, she worked as a postdoctoral research fellow in Dr. John C. Rogers's lab at the Institute of Biological Chemistry, Washington State University, USA. In 1999, she moved to Dr. Steve Jacobsen's lab in the Department of Molecular, Cell and Developmental Biology, University of California at Los Angeles, where she studied DNA and histone methylations using the model plant Arabidopsis. Dr. Cao won The Young Talented Investigator Award, Chinese Academy of Sciences (CAS) in 2002. Since 2003, she has been back in China as a Principle Investigator in the Institute of Genetics and Developmental Biology (CAS). She received The National Outstanding Young Investigator Award, National Natural Science Foundation of China in the same year and was elected as Academician of Chinese Academy of Sciences in 2015.

Dr. Cao's study focused on epigenetic and small non-coding RNA regulations of plant development. During her postdoc research in the USA, she carried out pioneering work on Arabidopsis methyltransferases CMT3 and DRM2, which are responsible for de novo and the maintenance of DNA methylation to maintain epigenetic gene silencing. Since her return to China in 2003, she has carried out extensive studies on Arabidopsis and rice, and has made numerous achievements.

\section{Identification of a dozen key factors involved in histone methylation and demethylation in higher plants}

Dr. Cao identified SDG714, a histone H3K9 methyltransferase that is involved in retrotransposon Tos17 DNA methylation and transposition in rice (Ding et al., 2007). This work primarily builds a connection between histone H3K9

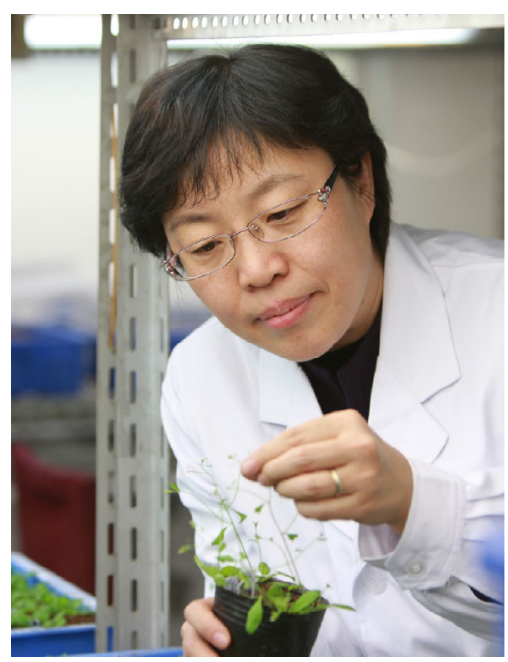

methylation and transposition in plants. Additionally, she identified the Jumonji C domain-containing protein JMJ703 that serves as an active $\mathrm{H} 3 \mathrm{~K} 4$-specific demethylase to mediate transposable elements (TEs) silencing in rice (Cui et al., 2013). She also initiated a system for histone demethylase assay and identified Arabidopsis REF6 as the first plant H3K27 demethylase. Dr. Cao showed that REF6, together with LHP1, has the ability to act in H3K27me3-mediated gene silencing (Lu et al., 2011). This work fills a gap in our understanding of histone modifications in plants.

\section{Mechanistic insight into the protein arginine methyl- transferases (PRMTs) that regulate gene expression at post-ranscriptional level}

Dr. Cao's work revealed that Arabidopsis PRMT10, 5 and $4 \mathrm{a} / 4 \mathrm{~b}$ control flowering by modulating FLOWERING LOCUS C (FLC) transcript levels, thus adding a new layer of complexity to flowering regulation and underlining the importance of PRMTs in plant development (Niu et al., 2007). She was the first to show that Arabidopsis PRMT5 regulates flowering via impacting alternative splicing of FLOWERING LOCUS KH DOMAIN (FLK) transcript (Deng et al., 2010; Pei et al., 2007). This work uncovers an important role of PRMTs in pre-mRNA splicing. She also showed that PRMT3 is linked to proper pre-rRNA pro- 
cessing in Arabidopsis, and PRMT3 is required for the balance between different pre-rRNA processing pathways (Hang et al., 2014). This work sheds light on PRMT functions and the regulation of ribosome biogenesis in both plants and animals.

\section{Identification of the key components involved in small RNA action in rice}

Dr. Cao's extensive investigations of the rice Dicer proteins demonstrated that OsDCL1, 4 and $3 b$ are responsible for the distinct small RNA biogenesis pathways in rice (Liu et al., 2007; Song et al., 2011; Wang et al., 2013). She provided the first evidence that OsDCL3a produces 24-nt small interfering RNAs (siRNAs) that are associated with miniature inverted repeat transposable elements (MITEs) for controlling important agricultural traits (Wei et al., 2014).

Dr. Cao made a great contribution to China and international plant sciences. She co-chaired several international conferences including the International Symposium on Epigenetic Regulation in Higher Plants (2012) and the Frontiers of Plant Biology-Plant Epigenetics in Growth and Development, Cold Spring Harbor Asia (2015). Since 2009, she has been the member of the International Steering Committee of Epigenomics of Plants International Consortium (EPIC). She also serves as the deputy editor-in-chief of Science China Life Sciences, and an editor of many international journals including The Plant Cell, Current Opinion in Plant Biology and Journal of Genetic and Genomics. Dr. Cao has been invited to present speeches at many international conferences. By collaborating with international scientists and organizing international meetings, she has greatly promoted academic research in China. She was selected as DuPont Young Professor in 2008. In 2010, she won National Outstanding Scientist Awards. In the same year, she received L'OLEAL Young Female Scientists Awards. She was also enrolled as a Leading scientist in "10 thousand program".

Cui, X., Jin, P., Cui, X., Gu, L., Lu, Z., Xue, Y., Wei, L., Qi, J., Song, X., Luo, M., An, G., and Cao, X. (2013). Control of transposon activity by a histone H3K4 demethylase in rice. Proc Natl Acad Sci USA 110, 1953-1958.

Deng, X., Gu, L., Liu, C., Lu, T., Lu, F., Lu, Z., Cui, P., Pei, Y., Wang, B., $\mathrm{Hu}, \mathrm{S}$., and Cao, X. (2010). Arginine methylation mediated by the Arabidopsis homolog of PRMT5 is essential for proper pre-mRNA splicing. Proc Natl Acad Sci USA 107, 19114-19119.

Ding, Y., Wang, X., Su, L., Zhai, J., Cao, S., Zhang, D., Liu, C., Bi, Y., Qian, Q., Cheng, Z., Chu, C., and Cao, X. (2007). SDG714, a histone H3K9 methyltransferase, is involved in Tos17 DNA methylation and transposition in rice. Plant Cell 19, 9-22.

Hang, R., Liu, C., Ahmad, A., Zhang, Y., Lu, F., and Cao, X. (2014). Arabidopsis protein arginine methyltransferase 3 is required for ribosome biogenesis by affecting precursor ribosomal RNA processing. Proc Natl Acad Sci USA 111, 16190-16195.

Liu, B., Chen, Z., Song, X., Liu, C., Cui, X., Zhao, X., Fang, J., Xu, W., Zhang, H., Wang, X., Chu, C., Deng, X., Xue, Y., and Cao, X. (2007). Oryza sativa dicer-like4 reveals a key role for small interfering RNA silencing in plant development. Plant Cell 19, 2705-2718.

Lu, F., Cui, X., Zhang, S., Jenuwein, T., and Cao, X. (2011). Arabidopsis REF6 is a histone H3 lysine 27 demethylase. Nat Genet 43, 715-719.

Niu, L., Lu, F., Pei, Y., Liu, C., and Cao, X. (2007). Regulation of flowering time by the protein arginine methyltransferase AtPRMT10. EMBO reports 8, 1190-1195.

Pei, Y., Niu, L., Lu, F., Liu, C., Zhai, J., Kong, X., and Cao, X. (2007). Mutations in the Type II protein arginine methyltransferase AtPRMT5 result in pleiotropic developmental defects in Arabidopsis. Plant Physiol 144, 1913-1923.

Song, X., Li, P., Zhai, J., Zhou, M., Ma, L., Liu, B., Jeong, D.H., Nakano, M., Cao, S., Liu, C., Chu, C., Wang, X.J., Green, P.J., Meyers, B.C., and Cao, X. (2011). Roles of DCL4 and DCL3b in rice phased small RNA biogenesis. Plant J. 69, 462-474.

Wang, L., Song, X., Gu, L., Li, X., Cao, S., Chu, C., Cui, X., Chen, X., and Cao, X. (2013). NOT2 proteins promote polymerase II-dependent transcription and interact with multiple MicroRNA biogenesis factors in Arabidopsis. Plant Cell 25, 715-727.

Wei, L., Gu, L., Song, X., Cui, X., Lu, Z., Zhou, M., Wang, L., Hu, F., Zhai, J., Meyers, B.C., and Cao X. (2014). Dicer-like 3 produces transposable element-associated 24-nt siRNAs that control agricultural traits in rice. Proc Natl Acad Sci USA 111, 3877-3882.

Open Access This article is distributed under the terms of the Creative Commons Attribution License which permits any use, distribution, and reproduction in any medium, provided the original author(s) and source are credited. 